and says she has not felt the motion of furred, and he complains of a bitter taste the chill for a day or two. She was in the mouth in a morning. Considering treated as were the first two cases, with that the disease arose from some morbid decided benefit, but premature labour affection of the nervous system, I ordered commenced on the fourth or fifth day the following; March 16:-

from my first seeing her, and the child was still-born for want of timely assistance, it being a footling case, and the head being lodged in the passages for sometime before I could visit her, with the chin wedged against the pubis. Even in this case the lead arrested the hemorrhage, although, from the gravid state of the uterus, the vessels must have been in a very active condition, and much more disposed to pour furth their contents than in simple menorrhagia.

lt would be useless to multiply cases after the above, but I may be allowed to add that $I$ have found no single remedy more successful in any disease, than lead and opium combined, in all discharges from the uterus and neighbouring parts. With respect to bleeding after the hemorrhage has ceased, I have already said enough. Iisfranc seems to use it as a revalsive agent, but I chiefly use it to relieve the head, which suffers, more or less, congestively, from the opium, as well as from the metastatic effects of a distant and quickly averted hemorrhage.

Southampton, May 2, 1835.

\title{
CASE OF CHOREA
}

TREATED WITH LARGE DOSES OF THE

\section{CARBONATE OF IRON.}

\section{By Chas. Robt. Bree, Esq., M.R.C.S., Stowmarket.}

S. Clarke, ætat. 25, of a spare habit of body, has been for the last five years af fected with chorea in the form of a convulsive rotary motion of the head, which, with one or two exceptions, has been unintermittent. The body occasionally assumes a similar acrion, which in each case has been much increased by over-exertion, of by anything which has occasioned depression of spirits. He has been frequently under medical treatment, from which he has occasionally found temporary beriefit; but he says that he found no relief fron bleeding application of blisters, setons, \&c.: on nation a slight trernulous motion of the the contrary, he always considered that head may be perceived. He says he is they did harm. His bowels are regular; quite well. Habeat Ferri Carbon. 3 iij his pulse is weak and 16 ; his appetite is ter die.

various, occasionally indifferent, but some-| 12. Continues to improve very fast. times morbidly great; his tongue is rather, Ordered to discontinue all medicines for perstet in usu baln. pluv.

April 3. Says he has caught cold, and does not feel so well; the nervous affection is, however, upon the whole much better; complains of slight pain in the head; has had cold chill and night sweats. Omitt. Ferri Carbon. et Pil. Hydrary. B. Hyd.c. Creta gr. v; Pulv. Antim. Feb. gr. iij. M. ft. pulv, hac et crastina nocte sumendus. Bo Magnes. Sulph. Ziss; Vin. Ipecac. f. $3 \mathrm{ij}$; Liq. Ammon. Acet. f. $\mathrm{j}$; Aq. Menthe $\xi v i i j ;$ M. ft. Mixt. de quis sunatur cochl. magna iij ter die.

April 6. Is better - the febrile symptoms have subsided. Habeat Ferri Carbon. $\mathrm{j}$ ter die ex theriaco.

9. Is much better. Has not pereived any convulsive motion of the head Gent., aa. gr. iij. M. Ft. pil. ii on hiss.

Bo Ferri Carbon. Precip. эj; Pulv. Rhei gr. iij. M. Ft. pulv. ex theriaco ter die sumendus. Utat. balneo pluviale quotidie, primo mane.

March 19. Says he is much the same; the bowels have been open three or four times in the day. Contin. pilulæ. Habeat Ferri Carbon. jii ter die, sine pulv. Rhei. 22. Thinks himself better; the action of the head is less violent; the bowels have been relaxed, and he complains of the foulness of his tongue in the morning. B Hydr. c. Creta gr. iij ; Extr. Conii gr. ij. M. Ft. pil on hss. Habeat Ferri Carbon. iij ter die.

25. Is much better; the convulsive mohe of the head has very much abated; Bowels not so open as they were. Contin. pilulæ. Habeat Ferri Carbon. 3 ss ter die.

28. Is evidently much better; the motion of the head is much slower and less violent than it was. He complains of an inward trembling; bowels open two or three times a day; pulse 90, still weak. Contin. pilulze. Habeat Ferri Carbon. $5 \mathrm{v}$ ter die.

31. Is much better. Aug. dosi Ferri Carbon. ad $5^{v j}$ ter die ss. Cont. Pil. et 
the present, and to use the shower-bath occasionally.

16. There is not the slightest motion of the head perceptible. He complains of faintness, and occasionally an "inward trembling;" the bowels are regular, and still dark, from the effects of the iron; his tong te is rather furred in the morning. Ordered a common dyspeptic pill, three times a day.

26. Is quite well. Has becn at work since last report, and has had no return of the complaint.

May 3. Continues quite well.

The above case is extracted verbatim from my case-book. The quantity of the Carbonate taken from March 16th to April 12th amounts to thirty-two ounces five drachms. I was only obliged to omit it once during that time.

Stowmarket, Suffolk, May 3, 1835.

ON THE HYPOTAESIS OF THE

\section{VASCULARITY OF THE TEETH.}

\section{To the Editor of THE LanceT.}

Srn - The insertion of the following remarks on the above subject, with reference to dental surgery, will afford me much gratification, and will, I trust be acceptable to your junior medical readers, as briefly detailing the opinions and discoveries of the great anatomical authorities on the teeth. I beg to preface the paper with the remark from Magendie's lectures, that "By adhering closely to facts, by taking nothing for granted which we are unable to prove, and, above all, by employing our senses in the investigation of the physiological conditions of the different tissues, we have been able to understand several points of physiology which were before unintelligible, or were obscured by vain and imaginary theories." I am, Sir, your obedient servant,

William Prckering, Dentist.

21, Vere Street, Cavendish Square, April 28th, 1835.

It is a subject of general regret and complaint with the profession, that the practice of dental surgery is yet so little in harmony with the present advanced state of anatomical and physiological science, but still remains the almost undisputed stronghold of ignorance and empiricism. In vain for it have anatomy and physiology unfolded their treasures; in vain have such men as Hunter, Cuvier, Sir C. Bell, Blain- ville, Lawrence, Geoffroy St. - Hilaire, Samuel Cooper, and others, published their labours and discoveries. Dentists seem totally unconscious of their existence, and dentistry still remains a by-word for jesters. There are, undoubtedly, many honomable exceptions anongst them,men of deserved repute, who would wish to see an altered state of things.

On a correct idea of the anatomy of the teeth and their connexions, alone, can a successful treatment of their diseases be established. It is necessary to be conver: sant with the membranes, and the formation of the pulp or rudiment, as they exist in foetal life. Authors differ as to the precise period at which the rudiments may be discoverch. Dr. Blake, in his excellent treatise on the teeth, states that he perceived them as early as four months after conception. Monsieur Serres, a French anatomist, mentions three months; and another author,* whose singular assertions I shall have occasion to notice hereafter, assures us that he has perceived them at two months after conception; that is to say, at a period when not only the or: garization of the jaws themselves, but that of any part of the system, has scarcely proceeded, so far as our senses can determine, beyond a confused and gelatinous mass! I never was myself, however, able to see anything of the rudiments of the teeth hefore the fourth or fifth month, at which period the twenty deciduous, and the four anterior, permanent molares, may be seen in a groove on the jaw-bone. "These rudiments," says Dr. Blake, "are so intimately connected with the gum, that they seemed derived from it, and came with it, when torn from the groove in the jaw, leaving behind the vessels and nerves with which they had been in contact." The pulp, or rudiment itself, appears to be a gelatinous substance, having a double involucre, which Cuvier has ingeniously compared to the double folding of a nightcap. The following sketch will convey an idea of the pulp, as it is found in foetal life, previous to the deposition of the enamel and ivory of the tooth.

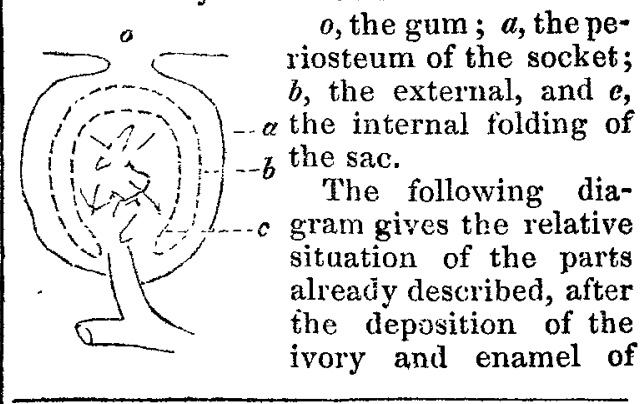

* T. Bell's Anatomy, Physiology, and Diseases of the Teeth, 8vo, London. 